\title{
Liver Derangement During COVID-19 Pandemic: What We Have Learnt?
}

\author{
C Rinaldi A Lesmana \\ Division of Hepatobiliary, Department of Internal Medicine, Faculty of Medicine \\ Universitas Indonesia/Dr. Cipto Mangunkusumo General National Hospital, Jakarta
}

Liver disease is still a major problem in the world. In the view of clinical course of the disease, there are many types of liver derangement, such as mild asymptomatic disease, chronic active disease, compensated or decompensated liver cirrhosis (LC), acute liver failure (ALF), acute on chronic liver failure (ACLF), and liver cancer (hepatocellular carcinoma/HCC). Early recognition of liver disease is the main key to prevent the disease progression or advance complications. However, it would need a comprehensive evaluation which is mostly should be done in the hospital. ${ }^{1}$

In the beginning of COVID-19 pandemic season, hospital visit has been hardly influenced by people's feared since it is considered that hospital is the most dangerous place to go and people will be easily infected by the virus. However, since liver disease is also considered as a silent disease, this clinical dilemma has been raised by all liver society in the world. ${ }^{2}$

The basic examination which is well-known in the population is the liver enzyme, such as alanine aminotransferase (ALT) and aspartate aminotransferase (AST). However, the liver enzyme is not always an ideal parameter to diagnose liver derangement and also cannot be used to recognize or monitor liver disease progression. Despite the clinical manifestations and blood test, transabdominal ultrasound and transient elastography (TE/Fibroscan) have been widely used to detect more accurate the liver disease progression. On the other hand, the etiology of liver disease investigation is also an important thing to do because the right management will also determine the patient's prognosis. ${ }^{3,4,5}$ It has been known that COVID-19 patients with increase AST also has poor prognosis. ${ }^{6,7}$

Portal hypertension is the main complication of LC as it can further lead to the development of esophageal varices and gastric varices, hepatic encephalopathy, massive ascites, hepatorenal syndrome as well as hepatopulmonary syndrome. Variceal bleeding is the most feared complication as it can cause high mortality, even though patients' survival is mostly determined based on the stage of liver disease which is usually measured with Child Pugh Score (CPS). It has been recommended that endoscopy screening should be performed in all newly diagnosed LC patients. ${ }^{89}$ Recent articles have shown the role of combination between TE and platelet count to detect the presence of esophageal varices, however, there is still a debatable about this to be used in the real clinical practice. ${ }^{10}$ In the era of COVID-19 pandemic season, medication has become the first choice to prevent complications, especially the use of beta blocker for primary prophylaxis as well as the use of vasopressor agent for active bleeding due to the aerosol risk of endoscopic procedure. However, in the acute active bleeding situation sometimes endoscopic procedure for variceal band ligation or histoacryl injection cannot be avoided. ${ }^{11}$ With regard to this situation, there should be a complete pre-assessment for patients and also complete personal protective equipment (PPE) provided before the procedure to be done..$^{12,13}$

Another issue in patients with $\mathrm{HCC}$, where this can be found not only in LC patients, but also in liver disease patients without cirrhosis, such as chronic hepatitis B patients or non-alcoholic fatty liver disease (NAFLD) patients. Based on clinical guidelines, screening and surveillance should be done every three to six months through trans abdominal ultrasound and the measurement of alpha-fetoprotein (AFP) level. Early recognition of liver nodule or early HCC might place the radio frequency ablation (RFA) treatment ultrasound guided as the possible first line treatment rather than liver resection to prevent the length of hospital stay and minimize procedure-related complications. In the management of advance $\mathrm{HCC}$, targeted therapy has been considered as the first line treatment despite trans-arterial chemoembolization (TACE). ${ }^{11}$

In conclusions, liver derangement in the COVID-19 pandemic season should not be forgotten. New strategy approach and patients' education are needed to prevent liver disease progression. 


\section{EDITORIAL}

\section{REFERENCES}

1. Sarin SK, Kumar M, Eslam M, George J, Mahtab MA, Akbar SM, et al. Liver diseases in the Asia-Pacific region: a lancet gastroenterology \& hepatology commission. Lancet Gastroenterol Hepatol 2020;5:167-228.

2. Boettler T, Newsome PN, Mondelli MU, Maticic M, Cordero E, Cornberg M, et al. Care of patients with liver disease during the Covid-19 pandemic: EASL-ESCMID position paper. JHEP Reports. 2020.

3. Kwo PY, Cohen SM, Lim JK. ACG Clinical Guideline: Evaluation of abnormal liver chemistries. Am J Gastroenterol 2017;112:18-35.

4. Gibson S. Diagnosis of chronic liver disease: An Overview. British J Healthcare Management 2016;22:348-53.

5. Castera L, Friedrich-Rust M, Loomba R. Noninvasive assessment of liver disease in patients with nonalcoholic fatty liver disease. Gastroenterol 2019;156:1264-81.

6. Jothimani D, Venugopal R, Abedin MF, Kaliamoorthy I, Rela M. COVID-19 and liver. J of hepatol 2020;x:x-x.

7. Darnindro N, Mokoagow I, Manurung A, Nasarudin J, Wardoyo EY, Sari AP. Association of aspartate aminotransferase (AST) and alanine aminotransferase (ALT) with mortality in patients with Coronavirus Disease 2019 (COVID-19) in Fatmawati General Hospital: a preliminary data. Gastroenterol Hepatol Dig Endosc 2020;21:89-94.

8. Simonetto DA, Liu M, Kamath P. Portal hypertension and related complications: diagnosis and management. Mayo Clin Proc 2019;94:714-26.

9. Garcia-Tsao G, Abraldes JG, Berzigotti A, Bosch J. Portal hypertensive bleeding in cirrhosis: risk stratification, diagnosis, and management: 2016 practice guidance by the American Association for the Study of Liver Diseases. Hepatol 2017;65:310-35.

10. Lesmana CRA, Raharjo M, Gani RA. Managing liver cirrhotic complications: overview on esophageal and gastric varices. Clin Mol Hepatol 2020 (Article in press).

11. Wong GLH, Wong VWS, Thompson A, Jia J, Hou J, Lesmana $\mathrm{CR}$, et al. Management of patients with liver derangement during the COVID-19 pandemic: an Asia-Pacific position statement. Lancet Gastroenterol Hepatol 2020;5:776-87.

12. Chiu PWY, Ng SC, Inoue H, Reddy DN, Hu EL, Choo JY, et al. Practice of endoscopy during COVID-19 pandemic: position statements of the Asian Pacific Society for Digestive Endoscopy (APSDE-COVID statements). Gut 2020;0:1-6.

13. APASL Covid-19 Task Force, Lau G, Sharma M. Clinical practice guidance for hepatology and liver transplant providers during the COVID-19 pandemic: APASL expert panel consensus recommendations [serial online] [cited 2020 August 17] Hepatol Int 2020. Available from: https://doi.org/10.1007/ s12072-020-10054-w. 